\title{
Radiografi sebagai alat penunjang diagnosa dan kontrol persembuhan laminitis pada kuda
}

\author{
Budhy Jasa Widyananta $^{1, *}$, Fitri Dewi Fathiyah ${ }^{2}$, Wakhid Nur Hidayat ${ }^{2}$ \\ ${ }^{1}$ Departemen Klinik Reproduksi dan Patologi, Fakultas Kedokteran Hewan, Institut Pertanian Bogor, Bogor \\ ${ }^{2}$ Praktisi Equestrina, Bogor
}

ABSTRACT: Laminitis is an inflammation of hoof laminae which support the pedal bone to stay to it normal position. One crossbreed horse was found severely lame and lying down most of the time. Lameness examination showing bilateral lameness of his fore hooves. Both are pain on the hoof test and digital pulse was positive. First X-ray were taken and show rotation and abnormal tip of the pedal bone, where the left fore was worse. Hoof trimming, corrective shoeing, sistemic and oral antiinflammatory, cold compress, feeding programe were combined for the treatment. Three months later, the horse was reexamined and $\mathrm{x}$ ray was taken. Another trimming and shoeing were followed with series of $\mathrm{x}$ ray shown good result. There are many different method have been suggested to provide support for an unstable pedal bone. Hoof wall resection and corrective sole on the heel area for corrective shoeing. Horse was trotted sound and start his lower level of work few months after. X ray may identify the rotation angle of pedal bone and their effect to the bone also guide the treatment of laminitis.

Keywords:

corrective shoeing, horse, hoof trimming, laminitis, $\mathrm{x}$ ray

\section{- PENDAHULUAN}

Laminitis adalah peradangan kuku kuda yang mendukung tulang pedal untuk tetap berada pada posisi normal (Morrison 2004). Peradangan kuku pada jaringan yang ada didalam kuku sering tidak tampak saat dilakukan inspeksi sehingga diagnosa penunjang diperlukan untuk melihat keparahan radang yang terjadi didalamnya. Diagnosa penunjang yang dapat dipergunakan untuk melihat jaringan keras seperti pertulangan kaki dapat dilakukan dengan menggunakan radiografi (Ross dan Dyson 2010). Tulisan ini kemudian melaporkan penggunaan teknologi pencitraan radiografi sebagai alat penunjang diagnosa dan kontrol persembuhan laminitis pada kuda.

\section{- KASUS}

Anamnesis: Seekor kuda mengalami kepincangan pada kaki depannya dan sering berbaring. Pemeriksaan klinis: Denyut jantung dan frekuensi nafas sedikit meningkat menunjukkan respon sakit. Kuda tidak mampu berlari derap (trot) sama sekali akibat rasa sakit. Vesitasi kuku dengan tang kuku menunjukkan rasa sakit di daerah toe. Alat dan bahan: Alat yang digunakan adalah satu set generator $\mathrm{x}$ ray, apron, marker, iluminator, dan kamera sedangkan bahan yang digunakan adalah seekor kuda crossbreed. Metode: Pengambilan gambar x-ray dilakukan dari lateral view dengan menggunakan marker berupa kawat lurus yang dipasang sepanjang dinding kuku. Besar Kilo Volt Peak $(\mathrm{kVp})$ dan $\mathrm{mAs}$ disesuaikan dengan obyek yang diamati dan setelah generator $\mathrm{x}$-ray. Pencitraan pada pengamatan ini digunakan $\mathrm{kVp} 54$, mAs 0,8, dan jarak fokus dengan target (FFD) $50 \mathrm{~cm}$. Generator diarahkan sejajar dengan kuku dan plate dengan titik fokus pada koronet (coronary band). Pengamatan citra radiografi hasil x-ray dilakukan pada iluminator. Parameter dan analisa data: Indikator pengamatan adalah mengamati perubahan sudut dorsal phalanx III terhadap dinding kuku (hoof wall), mengamati homogenitas lamina, dan mengamati adanya kelainan pada ujung tulang phalanx III. Adanya kelainan pada regio di atas kuku dijadikan catatan tambahan

\section{- HASIL DAN PEMBAHASAN}

Hasil pemeriksaan x ray menunjukkan adanya rotasi tulang phalanx III pada kedua kaki depan diikuti perubahan bentuk dari ujung tulang phalanx III. Kaki kiri menunjukan rotasi yang lebih tinggi daripada kaki kanan. Kuda didiagnosa mengalami laminitis bilateral (Gambar 1). Diduga pemberian pelet tidak diturunkan volumenya walaupun kuda sedang diistirahatkan karena pincang. Hal ini menimbulkan kelebihan konsumsi karbohidrat. Belknap (2017) mengatakan bahwa pemberian karbohidrat yang berlebih akan meningkatkan produksi asam laktat yang dapat membunuh mikroflora normal pencernaan dan menghasilkan endotoksin yang merusak lamina kuku.

Diterima: 14-04-2018 | Direvisi: 10-05-2018 | Disetujui: 31-06-2018 (C) 2018 CC-BY-SA. Ini adalah artikel Open Access yang didistribusikan berdasarkan ketentuan dari Creative Commons Attribution ShareAlike 4.0 International License (https://creativecommons.org/licenses/by-sa/4.0/). 

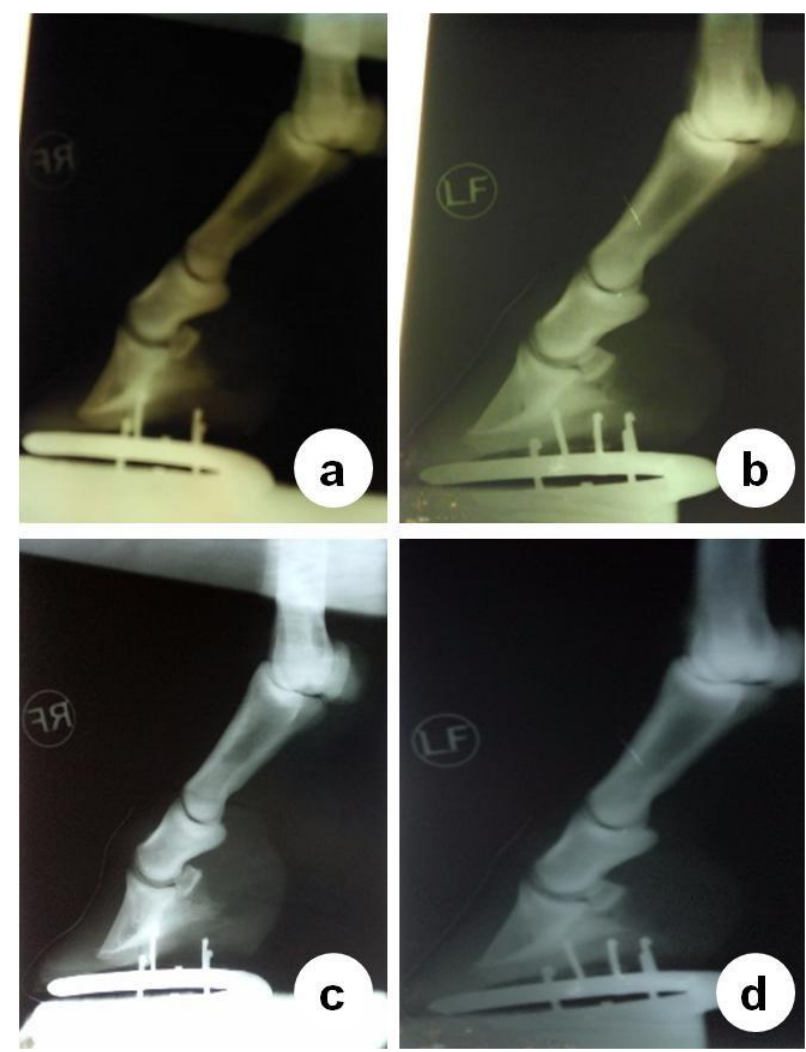

Gambar 1. Radiografi kuku kuda sebelum (a,b) dan setelah 3 bulan pascaterapi (c,d). Catatan: (a,c) kanan depan dan (b,d) kiri depan.

Menurut Rose dan Hodgson (2000) pada kasus laminitis kronis perlu dilakukan pemotongan kuku di bagian heel karena supply darah di coronary band bagian heel lebih besar dibanding depan agar tinggi heel tetap normal dan menjaga bentuk toe tetap normal agar dapat melakukan pergerakan dengan baik. Perbaikan posisi kuku dapat diamati dengan X- Ray dari lateral view. Pemotongan kuku dan penapalan dilakukan setiap dua minggu sekali oleh tukang tapal (farrier). Ladam yang digunakan adalah reverse shoe.

Reseksi atau pembuangan wall dilakukan jika terjadi pemisahan lamina dari phalanx 3 atau coffin bone atau wall tumbuh berlebih menekan coronary band sehingga menghambat pertumbuhan kuku yang baru secara normal, hal ini di ungkapkan oleh Rose \& Hodgson (2000). Menurut Hickman dan Humphrey (1994) adanya tekanan pada daerah sole menyebabkan rasa sakit pada saat menumpu sehingga pemakaian tapal dan alas kandang yang tebal akan membantu mengurangi rasa sakit.

Pemberian antiinflamasi sistemik seperti flunixin diikuti dengan pemberian phenilbutazone oral selama hampir satu bulan dapat diikuti pemberian obat pencegah gastric ulcer. Pemberian suplemen kuku yang mengandung biotin, methionin, dan zinc dilakukan dua kali sehari. Kuda dipuasakan dari pelet, diberi alas kandang tebal, kompres dingin, dan diistirahatkan total.

Tiga bulan kemudian, kembali kuda di x ray, dipotong kukunya dan di pasang tapal reverse shoe yang baru, kemudian kuku di $\mathrm{x}$ ray ulang. Hasil $\mathrm{x}$ ray terakhir menunjukkan posisi tulang phalanx III telah jauh membaik. saat kuda dibawa trot, terlihat bahwa kuda mampu berlari dengan baik

\section{- SIMPULAN}

Penggunaan radiografi khususnya $\mathrm{x}$ ray pada kuku dapat megidentifikasi derajat rotasi dan abnormalitas pada tulang phalanx III akibat kasus laminitis, namun juga dapat mengawal perkembangan persembuhan kasus laminitis.

\section{n INFORMASI PENULIS}

Penulis untuk Korespondensi

*BJW: dr.budhy_nanta@yahoo.com

Departemen Klinik Reproduksi dan Patologi, Fakultas Kedokteran Hewan, Institut Pertanian Bogor, Jalan Agatis Kampus IPB Dramaga Bogor 16680.

\section{- PUSTAKA ACUAN}

Belknap JK. 2017. Laminitis in Horses (Founder). http://www.msdvetmanual.com/musculoskeletalsystem/lameness-in-horses/laminitis-in-horses.

Hickman J, Humphrey M. 1994. Hickmans Farriery. Second Edition. Hollen Street Press: London.

Morrison S. 2004. Foot management. Clinical Techniques in Equine Practice. 3(1): 71-82

Rose RJ, Hodgson DR. 2000. Manual of Equine Practice. $2^{\text {nd }}$ Edition. W.B Saunders.

Ross MW, Dyson SJ. 2010. Diagnosis and Management of Lameness in the Horse-E-Book. Elsevier Health Sciences 